\title{
artigo
}

\section{Percepções de pessoas com estomia intestinal acerca da sua qualidade de vida}

Perception of people with intestinal ostomy about their quality of life

Percepción de las personas con ostomía intestinal sobre su calidad de vida

\section{RESUMO}

Objetivos: conhecer a percepção de pessoas estomizadas intestinal acerca da sua qualidade de vida. Métodos: Estudo exploratório e descritivo de abordagem qualitativa. Realizado em um Serviço de Estomaterapia. Participaram do estudo 26 pessoas com estoma intestinal definitivo ou temporário com 18 anos ou mais. Os dados foram coletados em outubro e novembro de 2019, após aprovação do Comitê de ética em Pesquisa, sob parecer n²253/2019, por meio de questionário sociodemográfico e clínicos e entrevista semiestruturada. Os dados foram submetidos à Análise de Conteúdo. Resultados: A qualidade de vida de pessoas com estomia intestinal é afetada por complicações da estomia e as mudanças nos seus papéis sociais, bem como as alterações emocionais e fisiológicas decorrentes da estomização. Conclusões: Destaca-se que os efeitos positivos na qualidade de vida podem estar associados à forma como as pessoas reagem à sua própria estomia. A maioria dos participantes refere ter boa qualidade de vida.

DESCRITORES: Qualidade de Vida; Estomias; Enfermagem médico-cirúrgica.

\section{ABSTRACT}

Objectives: to know the perception of intestinal ostomized people about their quality of life. Methods: Exploratory and descriptive study with a qualitative approach. Performed at a Stomatherapy Service. Twenty-six people with permanent or temporary intestinal stoma aged 18 years or older participated in the study. Data were collected in October and November 2019, after approval by the Research Ethics Committee, under opinion No. 253/2019, through a sociodemographic and clinical questionnaire and semi-structured interview. The data were submitted to Content Analysis. Results: The quality of life of people with intestinal ostomy is affected by complications of the ostomy and changes in their social roles, as well as the emotional and physiological changes resulting from ostomy. Conclusions: It is noteworthy that the positive effects on quality of life may be associated with the way people react to their own ostomy. Most participants reported having a good quality of life.

DESCRIPTORS: Quality of Life; Ostomies; Medical-surgical nursing.

\section{RESUMEN}

Objetivos: conocer la percepción de las personas ostomizadas intestinales sobre su calidad de vida. Métodos: Estudio exploratorio descriptivo con abordaje cualitativo. Realizado en un Servicio de Estomaterapia. Participaron en el estudio 26 personas con estoma intestinal permanente o temporal de 18 años o más. Los datos fueron recolectados en octubre y noviembre de 2019, previa aprobación por parte del Comité de Ética en Investigación, bajo dictamen No. 253/2019, mediante cuestionario sociodemográfico y clínico y entrevista semiestructurada. Los datos se enviaron a Content Analysis. Resultados: La calidad de vida de las personas con ostomía intestinal se ve afectada por las complicaciones de la ostomía y los cambios en sus roles sociales, así como por los cambios emocionales y fisiológicos resultantes de la ostomía. Conclusiones: Es de destacar que los efectos positivos sobre la calidad de vida pueden estar asociados con la forma en que las personas reaccionan a su propia ostomía. La mayoría de los participantes informaron tener una buena calidad de vida.

DESCRIPTORES: Calidad De Vida; Estomas; Enfermería Médico-Quirúrgica.

RECEBIDO EM: 11/03/2021 APROVADO EM: 05/04/2021

\section{Prisciane Cardoso Silva}

Mestre em Enfermagem pelo Programa de Pós-Graduação em Enfermagem da Universidade Federal do Rio Grande.

ORCID: 0000-0001-5327-1785 


\section{Giovana Calcagno Gomes}

Doutora em Enfermagem, professora na Escola de Enfermagem, Universidade Federal de Rio Grande.

ORCID: 0000-0002-2464-1537

\section{Marina Soares Mota}

Doutora em Enfermagem, professora adjunta no Departamento de Enfermagem Hospitalar na Rede de Atenção, Faculdade De Enfermagem, Universidade Federal de Pelotas.

ORCID: 0000-0002-5717-9406.

\section{Daiane Porto Gautério Abreu}

Doutora em Enfermagem, professora na Escola de Enfermagem, Universidade Federal de Rio Grande.

ORCID: 0000-0002-1125-4693

\section{Fabiane Lopes dos Santos}

Enfermeira graduada pela Universidade Federal de Rio Grande.

ORCID: 0000-0001-9750-7008

\section{Juliane Portella Ribeiro}

Doutora em Enfermagem, professora adjunta no Departamento de Enfermagem Hospitalar na Rede de Atenção, Faculdade De Enfermagem, Universidade Federal de Pelotas.

ORCID: 0000-0002-1882-6762

\section{INTRODUÇÃO}

$\mathbf{T}$

ornar-se estomizado intestinal pode provocar sentimento de revolta, de tristeza e de desconstrução da autoimagem, devido à vivências e circunstâncias embaraçosas decorrentes da estomia, bem como devido a complicações como prolapsos, dermatites e outras ${ }^{1}$, alterando a qualidade de vida (QV). Observa-se que a intensidade dessa situação pode afetar particularmente cada indivíduo conforme sua capacidade adaptativa e emocional. A forma de enfrentamento dessa condição pode levar a sentimentos de exclusão, constrangimento e rejeição, com a possível diminuição da $\mathrm{QV}$ dessas pessoas ${ }^{2}$.

$\mathrm{O}$ conceito de QV está ligado à percepção do indivíduo sobre seu estado de saúde em relação aos domínios sociais, físicos, psicológicos, econômicos e espirituais ${ }^{3}$. Para as pessoas com estomias intestinais, a QV é ainda dependente de outros fatores, como adaptação psicológica à nova mudança, autoimagem, autoestima, complicações do estoma, adaptação aos equipamentos coletores, além de suporte adequado recebido de profissionais qualificados ${ }^{4}$.

As alterações ocasionadas pela estomização podem ser tão significativas que os sentimentos vivenciados podem levar a
As alterações

ocasionadas pela

estomização podem

ser tão significativas

que os sentimentos

vivenciados podem

levar a momentos

de depressão, medo,

tristeza, isolamento

social, além do

afastamento da

atividade laboral momentos de depressão, medo, tristeza, isolamento social, além do afastamento da atividade laboral ${ }^{5}$. Ainda, é necessário considerar a presença ou ausência de multimorbidades associadas, a manutenção de relacionamentos e interações sociais, sentimentos positivos e esperançosos, além das facilidades e entraves no acesso ao serviço de saúde e de apoio especializado e apoio familiar ${ }^{6}$.

A QV da pessoa com estomia é resultado de um conjunto de fatores facilitadores nesse processo de mudança tão relevante na vida dessas pessoas. Portanto, o cuidado de enfermagem permite que pessoas estomizadas aprendam sobre os cuidados voltados à saúde, ao estoma e como melhorar a QV através do autocuidado?.

Assim, questiona-se como a pessoa estomizada percebe sua QV? Diante do exposto, o presente artigo tem o objetivo de conhecer a percepção de pessoas estomizadas acerca de sua QV. Esse conhecimento torna-se essencial ao permitir que o cuidado de enfermagem seja realizado de forma ampliada a partir da percepção da pessoa a ser cuidado acerca de sua QV.

\section{MÉTOdO}

Trata-se de pesquisa qualitativa do tipo descritivo e exploratório realizada com 
pessoas com estomias intestinais atendidas no Serviço de Estomaterapia (SE) de um Hospital Universitário de um município do sul do Brasil. Utilizou-se como critérios de inclusão dos participantes: ter 18 anos ou mais, possuir estoma intestinal, possuir cadastro ativo no SE, ter condições físicas e mentais para responder às perguntas do estudo. Os critérios de exclusão limitaram-se à ausência nas consultas de enfermagem do SE, estar realizando quimio e/ ou radioterapia.

O número de participantes foi definido pela saturação8 dos dados, ou seja, quando não havendo novos elementos interrompeu-se a coleta. Assim, participaram 26 pessoas estomizadas intestinais com idades entre 29 a 80 anos, 14 eram homens e 12 mulheres em sua maioria por neoplasias colorretais.

A coleta de dados ocorreu em outubro e novembro de 2019 no consultório do SE, após parecer favorável do Comitê de Ética Em Pesquisa na Área da Saúde da Universidade Federal do Rio Grande Certificado de Apresentação de Apreciação Ética $\mathrm{n}^{\circ}$ 20012819.4.0000.5324, respeitou-se a Resolução CNS - 466/12. Utilizou-se um questionário com informações sociodemográficas e clínicas da pessoa com estomia e uma entrevista semiestruturada, aplicados durante as consultas de enfermagem. Na entrevista semiestruturada os participantes foram questionados acerca de suas percepções quanto a sua QV. O roteiro se baseia na revisão de literatura acerca dos aspectos que interferem na QV de pessoas com estomias intestinais. As entrevistas foram gravadas e posteriormente transcritas na íntegra.

Todos os participantes assinaram o Termo de Consentimento Livre e Esclarecido. Analisou-se os dados através da Análise de Conteúdo, desenvolvendo as etapas de pré-análise; exploração do material e tratamento dos resultados e, por fim, inferência e interpretação?.

\section{RESULTADOS}

A QV é construída a partir da percepção das pessoas acerca seus domínios sociais, físicos, econômicos, mas também psicológicos e espirituais. Assim, os participantes desse estudo demonstram em suas falas o impacto na $\mathrm{QV}$ ao viver com uma estomia.

\section{As transformações corporais impac- tando a QV}

O corpo físico estomizado transforma a autoimagem e a sua funcionalidade repercutindo na $\mathrm{QV}$ desses.

2 uando tens estomia, tens que colocar uma calça folgada.(P6)

No início é difícil, até a pessoa se adaptar, perde peso.(P12)

Gera um transtorno, porque a minha pessoa não está perfeitamente como era, não posso fazer força, não posso agachar para pegar peso, já muda muita coisa.(P14)

A continência é alterada podendo causar desconfiança quanto seu odor, bem como lesóes dolorosas pelo efluente em contato com a pele que impactam a $Q V$.

Não consigo segurar o gás, mas não fede porque não sai de dentro da bolsinha. Aí já começa todo mundo a rir.(P2)

Parecia que eu estava sempre fedendo, mas é impressão da cabeça da gente.(PS)

Eu tenho a pele muito sensivel e, agora mesmo, estou toda machucada em volta[do estoma]. Até para caminhar dói.(P20)

\section{Entre isolamento, medo, desespe- rança e felicidade}

Observa-se o isolamento bem como a desesperança e o medo frente as transformações do viver estomizado.

Nos primeiros meses eu fiquei bem desorientada. Eu fiquei muito nervosa, quase não falava com ninguém.(P11)

$O$ que adianta ficar, viver com isso? Eu não vivo, estou vegetando. Muitas vezes preferi a morte do que viver com isso.(P13)
Eu não comunico com ninguém, me isolei. Eu acho que sim, é pesada a cruz. Ai vem aquela palavra de novo: Mas estás vivo. E me pergunto, às vezes, até que ponto vale a pena me ver assim. Eu acho que a hora que eu morrer, eu vou descansar.(P15)

Mas é isso assim, que fico às vezes, um pouco em depressão. Porque eu quero ir aos lugares e não me animo, com medo.(P20)

A bolsa se torna a materialidade do sofrimento devido às limitações e o receio de contratempos com a mesma.

Estou debilitada nesse momento e é muito sofrimento para mim.(P13) Tem momentos dificeis. Tem coisas ainda à serem superadas. (P1)

Mudou todo o meu dia a dia, tem que cuidar dessa bolsa aqui $24 \mathrm{~h}$ por dia.(P10)

Afetar. Não ando sem camisa no verão, banho de praia faz 3 anos que não tomo, não durmo de barriga para baixo, algumas limitações. (P23)

Hoje em dia se eu tiver que viajar, não vou poder ou vou, mas vou ter que preparar um montão de coisas para conseguir viajar e me enquadrar dentro dela. Então, quer dizer que não é só vai e deu. Não é bem fácil tu conciliar uma coisa com a outra. (P10)

Tenho um descontentamento pelo medo de expelir gases em hora inadequada.(E15)

Há uma descaracterização do ser anterior a estomização, sendo a bolsa algo que aprisiona e consome a pessoa que a utiliza.

$A$ gente não pode fazer o que fazia. Sempre tem aquela preocupação. $A$ gente não está mais livre, só de ter esse empecilho. Sempre está aqui[a bolsa]. Tu sai, estás ali adiante e ela solta.(P11)

És uma pessoa normal e daqui a pouco estás com uma bolsinha. $\mathrm{Na}$ realidade isso representa como se 
fosse um parasita grudado em ti. Não é normal.(P12)

Apesar das falas negativas, há pessoas que se sentem felizes com o novo contexto de vida por perceberem ter mais $Q V$ com a estomia e a bolsa coletora.

Se afetou de algum jeito foi de maneira positiva, porque eu penso na minha cabeça que eu troquei um câncer por uma bolsa então acho que eu saí ganhando.(P9)

Mudou para melhor, tem pessoas que se sentem desgraçadas com uma bolsa, não me sinto assim, sou uma pessoa muito feliz, muito, muito feliz.(P7).

Olha acho que tenho qualidade de vida, não me falta nada, tenho tudo.(P26)

\section{Adaptações e restrições pelo novo contexto para melhoria da QV}

Os participantes relatam terem adaptado ou restringido algumas atividades frente às novas necessidades de saúde, fato que pode reduzir a $Q V$ desses.

Certos lugares a gente não pode estar muito. Eu participava de torneios, então assim já ficou mais difícil.(P16)

Só vou para a praia de camisa e não tomo mais banho de piscina ou de mar.(P18)

Eu não viajo, não consigo viajar. Para sair de manhã, não posso tomar café, por causa do intestino, as fezes ficam moles. Então, eu procuro não tomar café. (P20)

$A$ única coisa que eu fazia muito $e$ não faço mais é jogar futebol.(P21) Sinto-me constrangido quando estou com outras pessoas e acontece de sair gases. Evito jantar em casa de conhecidos porque bem na hora que a gente está se alimentando é a hora que sai.(P23)

Apesar das falas acima, há possibilidade de ter QV e um enfrentamento menos di- fícil, mas esse depende da subjetividade de cada pessoa e da construção feita sobre seu contexto de vida.

Eu sou bem assim, estou conversando e:_Ah, só um pouquinho que vou ver minha bolsa que está muito cheia de ar.(P7)

Vivo normal com todo mundo, nunca tive problema nenbum de relacionamento por causa da estomia e tem gente até que nem sabe que tenho. Eu também não conto porque não tem nada a ver, mas eu acho que vivo bem com isso e as pessoas também.(P9)

Não mudou nada. Não mudou a relação com outras pessoas, nem com minha família. (P17)

Nunca deixei interferir nos relacionamentos. Isso é uma questão individual, bem pelo contrário, me relacionei, sai, caminhei bastante, porque eu entendia que tinha que estar bem para enfrentar a doença. (P24)

\section{Esperança e fé em uma nova chance de viver}

A fé melhora a $\mathrm{QV}$ ao fortalecer e confortar a pessoa para enfrentar o cotidiano de vida estomizada com mais leveza.

O médico se apavorou que eu reagi muito bem. Eu tenho muita fé em Deus! Deus para mim é tudo.(P2)

Eu acredito em Deus e vamos levando. Eu costumo brincar que eu estou no lucro.(P11)

Sempre tive fé em Deus e até hoje continua assim.(P12)

É ter fé em Deus e seguir em frente. Não adianta querer ficar se traumatizando que não vai levar a nada, só vai ser mais prejudicado ainda. Então tens que seguir teu caminho.(P16)

Relatam a gratidão por estarem vivos por perceberem a estomização como uma segunda chance, o que lhes faz viver com mais qualidade.
Vou te repetir:_eu estou viva! Passei por várias coisas, mas o 'velhinho lá de cima' ainda não me quer lá. Não tomo remédio nenbum. Graças a Deus não tenho nada. Vou reclamar do quê?(P4)

Porque que depois da colostomia eu não volto à vida? Eu vi que era melhor, eu vi que estava perdendo de viver. Graças a Deus, Ele me deu mais uma chance de vida.(P7)

Acho que tem a mão de Deus, era para eu morrer. O que mais causou em mim foi a fé em Deus, de poder conseguir sobreviver através de uma estomia porque não teria saida. (P6)

Eu tenho bastante fé, já tinha e aí mais ainda. Foi significativo para mim. Eu acreditei que é uma forma para eu viver e criei fé. Fiz promessa, paguei, tudo aquilo. Achei que ia morrer antes, mas não, graças a Deus!(P17)

Melhorou, melhorou bastante. Aumentou ainda mais. Fiquei bem mais próxima de Deus. Não sou forte, a força vem de Deus, com certeza. Para ter passado tudo que eu passei nos últimos meses e estar aqui rindo contigo.(P19)

Eu comecei a rezar mais. Fazer oração e rezar mais.(P26)

Há a esperança que os avanços da medicina os auxilie a viver sem a bolsa coletora e consequentemente com mais qualidade.

Tem! A esperança é que com o avanço da medicina não vá mais precisar usar uma bolsinha, mas que vão criar alguma outra coisa que melhore a nossa qualidade de vida. É nisso que eu me apoio todos os dias. (P1)

\section{Redução do padrão de vida e quali- dade de vida}

O domínio econômico foi afetado pelo afastamento do trabalho pela estomização. Fato comprometer a QV pela redução do acesso a serviços, além 
da sensação de ser improdutivo e dependente.

A parte que mais me afetou foi a profissional. Teve impacto financeiro sim, diminuiu minha renda. Quando eu era normal eu trabalhava, ganhava bem, tinha uma vida normal do profissional e depois da estomia reduziu muito isso.(P6)

Era uma mulher que fazia congelados, trabalhava até aos domingos, natal, ano novo, e agora depender dos outros.(P13)

\section{DISCUSSÃO}

A percepção dos participantes é que a estomização impacta todos os campos da QV. Sobre o físico a estomia transforma a imagem e a funcionalidade do corpo. A imagem é edificada pela forma e contornos sendo que a insatisfação com o corpo pode gerar sentimentos negativos e inclusive levar a depressão ${ }^{10}$. Esse fenômeno ainda ocorre mesmo nos casos em que a pessoa é ciente da situação e aceita a nova condição sem dificuldades de adaptação ${ }^{11}$.

As questóes corporais influenciam no aspecto psicológico gerando isolamento, medo e desgosto com a vida. Ainda que esse fato seja assustador, a insatisfação com as novas condições de vida e a dúvida em relação à escolha pela estomização em favor da sobrevivência não surpreendem, já que ao vivenciarem o impacto que o tratamento cirúrgico acarreta, podendo considerar até mesmo a própria morte, ainda que a realização da estomia represente a diferença entre viver e morrer ${ }^{7}$.

Apesar de impactante, esse desejo se torna compreensível ao considerar os desafios que um estoma pode adicionar à vida dessas pessoas, já que as feridas da cirurgia e as preocupações sobre irritação da pele, risco de hérnia, medo de vazamentos, além de desconforto a outras pessoas fazem com que as pessoas com estomia sintam-se incapazes de manterem-se fisicamente ativas e não têm confiança para participar de atividades habituais ${ }^{12}$.

Geralmente, esses sentimentos estão
A percepção dos participantes é que a estomização impacta todos os campos da QV. Sobre o físico a estomia

transforma a imagem e a funcionalidade do corpo. A imagem é edificada pela forma

e contornos sendo

que a insatisfação

com o corpo pode

gerar sentimentos

negativos e inclusive

levar a depressão.

Esse fenômeno

ainda ocorre mesmo

nos casos em que a

pessoa é ciente da

situação e aceita a

nova condição sem

dificuldades de

adaptação. associados às restrições sociais e pensamentos intrusivos, além de preocupações com a vida social e insegurança da estomizado ao tentar recuperar papéis e funções sociais anteriores ${ }^{13}$. As mudanças decorrentes da estomização também envolvem a autoestima e as relaçôes interpessoais, emergindo assim, o medo de rejeição, o bloqueio na construção de novos relacionamentos, a vergonha do próprio corpo, o constrangimento pela utilização da bolsa coletora e, com isso, a dificuldade em falar sobre sua nova condição de vida ${ }^{14}$. Fatos que corroboram com a percepção dos participantes do estudo acerca do domínio social reduzido à $\mathrm{QV}$ desses.

$\mathrm{O}$ isolamento social é percebido em diversos momentos nas falas, ainda que seja parcial, como quando a pessoa mantém os contatos sociais, mas não fala sobre a estomia ou a escondem dos demais e o isolamento acaba por comprometer as atividades sociais, religiosas e de lazer. Os olhares impiedosos, estigmatizantes e excludentes acabam por afastar as pessoas do convívio social e torna-as reféns da percepção pública ${ }^{15}$.

É evidente que os participantes apresentam dificuldades em falar sobre aspectos de sua vida relacionados à estomia. Por vezes, apresentam-se introvertidos e evasivos, outros emocionados e desestabilizados. É comum que pessoas com estomias refiram viver em um ambiente muito inconveniente, apresentaram escores altos de estado depressivo e insatisfação com as atividades de lazer ${ }^{16}$.

A QV no aspecto econômico é percebida como afetado por reduzir o padrão de vida, pela sensação de improdutividade e de dependência com a estomização. Assim, a perda do controle esfincteriano é considerada um obstáculo ao retorno às atividades..$^{17}$ Além disso, o medo da exposição e o constrangimento induzem ao afastamento definitivo das atividades laborais. Situação que modifica a dinâmica familiar e socioeconômica ${ }^{15}$. O impacto disso pode ser intenso, já que essas pessoas provavelmente não conseguirão voltar à ocupação anterior e precisarão se readequar a uma nova funçãó

Apesar da percepção negativa nos domí- 
nios supracitados, observa-se que a construção da subjetividade do estomizado pode influenciar em melhores enfrentamentos e consequentemente melhor percepção quanto a sua QV. Além disso, fé, gratidão e esperança são aspectos do espiritual que elevam a $Q V$ por auxiliar na resignificação da estomização e confortar nos momentos de dificuldade, mantendo as pessoas focadas em seus cuidados de saúde ${ }^{1}$.

\section{CONCLUSÕES}

As pessoas estomizada percebem alterações em suas QV. Domínios físicos, psicológicos, sociais e econômicos são percebidos de forma negativa especialmente pela influencia das transformações da imagem, funcionalidade e a dependência da bolsa coletora. $\mathrm{O}$ espiritual se mostrou um campo que melhora a $\mathrm{QV}$ ao trazer conforto, esperança e fé.

A pesquisa apresenta a limitação de ser realizada em apenas um serviço de estomaterapia. Sugere-se que novas pesquisas qualitativas sejam realizadas em favor da QV das pessoas estomizada par fornecer novos subsídios para o enfermeiro desenvolver ações terapêuticas melhorem a $\mathrm{QV}$ e promovam a saúde das pessoas e de suas famílias. -

\section{REFERÊNCIAS}

1. Mota MS, Gomes GC, Petuco VM. Repercussions in the living process of people with stomas. Texto.Contextonferm[Internet].2016[cited 2019 mar.10];25(1):e1260014.Avaliable from:http://dx.doi.org/10.1590/0104-070720160001260014

2. Faria FL, Labre MM, Souza IF, Almeida RJ. Avaliação da qualidade de vida em pacientes com estomia intestinal. Arq.Ciênc. Saúde.[Internet]. 2018[cited 2020 mar. 10];25(2):08-14.Avaliable from:http://www.cienciasdasaude.famerp.br/index.php/ racs/article/view/924

3. Mcclees N, Hyland D, Bolton L. Quality Of Life With An Ostomy: Historic Perspective 1444. JWOCN.[Internet]. 2007[cited 2020 mar. 10];34(72).Avaliable from:https://journals.Iww.com/ jwocnonline/Citation/2007/05001/QUALITY_OF_LIFE_WITH _ AN_OSTOMY__HISTORIC.203.aspx

4. Maciel DBV, Dos Santos MLSC, Souza NVDO, Fuly PDSC, Camacho ACLF, Soares HPL. Qualidade de Vida de Pessoas com Estomias Intestinais Definitivos: uma Revisão Integrativa. Rev. Enfermagem Atual InDerme.[Internet].2018[cited 2019 abr 20];(86).Avaliable from:http://revistaenfermagematual.com/index.php/revista/article/view/109

5. Cirino HP, Kestenberg CCF, Caldas CP, do Nascimento Santos C, Ribeiro WA. Repercussões emocionais e processos adaptativos vividos por pessoas estomizadas. Saúde Coletiva (Barueri), 10(57), 3573-3596. Avaliable from: http://revistas.mpmcomunicacao.com.br/index.php/saudecoletiva/article/view/948

6. Fernandes C, Katherinne I, Liberato MD, Freitas SS, Melo LDM, Sena MF, Medeiros LP. Distúrbio na imagem corporal: diagnóstico de enfermagem e características definidoras em pessoas estomizadas. Aquichan, Bogotá, 17(3):270-83, 2017. Avaliable from: http://www.scielo.org.co/scielo.php?script=sci_abstract\& pid=S1657-59972017000300270\&lng=en\&nrm=iso\&tlng=pt

7. Mota MS, Gomes GC, Silva CD, Gomes VL, Pelzer MT, Barros E. Autocuidado: uma estratégia para a qualidade de vida da pessoa com estomia.Investig Enferm. Imagen Desarr[Internet].2016[cited 2019 abr 20];18(1):63-78. Avaliable from:http:// dx.doi.org/10.11144/Javeriana.ie18-1.aeqv

8. Thiry-Cherques HR. Saturação em pesquisa qualitativa: estimativa empírica de dimensionamento. Rev PMKT[Internet].2009[cited 2019 abr 20];;(3):20-7. Avaliable from:http://www.revistapmkt. com.br/Portals/9/Edicoes/Revista_PMKT_003_02.pdf

9. Bardin L. Análise de conteúdo. Lisboa: Edições 70; 2010.
10. Silva D, Ferriani L, Viana MC.Depression, anthropometric parameters, and body image in adults: a systematic review.Rev. Assoc.Med.Bras.[Internet].2019[cited 2019 mar 20];65(5):731738.Avaliable from:https://www.scielo.br/scielo.php?script=sci_arttext\&pid=S0104-42302019000500731

11. Marques ADB, Amorim RF de, Landim FLP, Moreira TMM, Branco JG de O, Morais PB de et al.Consciência corpórea de pessoas com estomia intestinal: estudo fenomenológico.Rev. Bras.Enferm. [Internet].2018[cited 2019 abr 20];71(2). Avaliable from: http://www.scielo.br/scielo.php?script=sci_arttext\&pid=S0034-71672018000200391\&lng=en

12. Saunders S, BRUNET J. A qualitative study exploring what it takes to be physically active with a stoma after surgery for rectal cancer. Supportive Care in Cancer. 27(4):481-1489, 2019. Avaliable from: https://pubmed.ncbi.nlm.nih.gov/30368673/

13. Cohee AA, Stump T, Adams RN, Johns SA, Von AHD, Zoppi K, et al.Factors associated with depressive symptoms in young longterm breast cancer survivors.Qual Life Res[Internet].2016[cited 2020 mar 10];25(8):1991-97.Avaliable from:https://link.springer.com/article/10.1007/s11136-016-1241-6

14. Cardoso DBR, Almeida CE, Santana ME, Carvalho DS, Sonobe HM, Sawada NO. Sexualidade de pessoas com estomias intestinais. RevRene.[Internet].2015[cited $2019 \mathrm{abr}$ 20];16(4):576-85.Avaliable from:https://www.redalyc.org/ pdf/3240/324041519015.pdf

15. Marques GS, Nascimento DC, Rodrigues FR, Lima CM, Jesus DF. A vivência de pessoas com estomia intestinal no grupo de apoio em um Hospital Universitário.Revista Hospital Universitário Pedro Ernesto[Internet].2016[cited 2019 abr 20];15(2):113-121.Avaliable from:https://www.e-publicacoes. uerj.br/index.php/revistahupe/article/view/28235

16. Park S, Jang IS, Kim YS. Risks for depression among ostomates in South Korea. Japan Journal of Nursing Science. 15(3):203-09, 2018. Avaliable from: https://onlinelibrary.wiley. com/doi/full/10.1111/jjns.12197

17. Ribeiro WA, Andrade M, Couto CS, Souza DMS, De Morais MC, Santos JAM. As contribuições do enfermeiro no autocuidado ao paciente estomizado: uma revisão integrativa. Revista Pró-UniverSUS [Internet].2019[cited 2019 abr 20];10(1):72-75.Avaliable from:http://editora.universidadedevassouras.edu.br/index. php/RPU/article/view/1683 